\title{
Consistency of Parents' and Teachers' Assessment of Emotional and Behavioral Problems in Children with Mentally Retarded
}

\begin{abstract}
Sema Kaner*
ABSTRACT: In this study it is examined parent and teacher agreement in behavioral and emotional problems of 206 children with mentally retarded from Turkish families. Children ages 5-20 years old were rated by parents and teachers on the Revised Problem Behavior Checklist. Results indicated that significant but low to moderate correlations between parent and teacher ratings at the scale and item levels. Implications for assessment of children with disabilities according to the outer informants are discussed.
\end{abstract}

Key Words: Mentally retarded children, parent and teacher, emotional and behavioral problems, Revised Problem Behavior.

\section{SUMMARY}

Purpose and Significance: Mentally retarded children have various behavior problems that many people have difficulty in dealing with them. Especially for school children, the two major sources of information about problem behaviors are parents and teachers. Problem behaviors most often indicated by parents and teachers in the home and school settings. In general, concordance has been found low to moderate suggesting that there may be differences in raters' frames of references and that children's behaviors vary in different settings. This study aimed at searching parent and teacher agreement in behavioral and emotional problems of children with mentally retarded.

* Prof. Dr. (Emeritus), Ankara University, Faculty of Educational Sciences, Dept. Of Special Ed., kaner@education.ankara.edu.tr 
Methods: The concordance between parents' and teachers' perceptions of behavioral and emotional problems of 216 children with mentally retarded was assessed using Revised Problem Behavior Checklist. Each child was rated by both his or her parent and teacher. Mean child chronological age was 11.37 ( $\mathrm{SD}=5.09$ age).

Results: Correlations between parents' and teacher scores across problem dimentions were significant on all of the subscales (Conduct Disorder, Anxiety-Withdrawal, Psychotic Behavior, Motor Excess) except two (Socialized Agression, Attention Problems-Immaturity). The results show significant but relatively low-to-moderate correlations among parents and teachers. Correlations between two informants ratings were higher on externalizing than internalizing problem behaviors on both scale and item levels. High levels of parent-teacher agreement were obtained only when rank orders of problem behaviors were compared.

Discussion and Conclusions: Our findings, in general confirm previous reports that suggested that agreements between raters are stronger for externalizing than internalizing types of problems. Results also showed that two informants were viewed childrens' problem behaviors somewhat differently. Our findings suggest informant and setting specifity of -parent and teacher-identified problem behaviors in children with mentally retarded. 


\title{
Zihin Engelli Çocukların Duygusal ve Davranışsal Problemlerinin Değerlendirilmesinde Anne-Baba ve Öğretmen Tutarlılığı
}

\begin{abstract}
Sema Kaner*
ÖZ. Bu çalışmada, zihin engelli çocukların ( $\mathrm{n}=206)$ duygusal ve davranışsal problemleri öğretmenlerinin ve anne-babalarının görüşlerine göre değerlendirilmiştir. Bu amaçla, her iki gruba da Yenilenmiş Problem Davranış Kontrol Listesi uygulanmıştır. İki bilgi kaynağının değerlendirmeleri alt ölçekler ve maddeler arasındaki ilişkilere göre incelenmiştir. Bulgular, Toplumsallaşmış Saldırganlık ve Dikkat Problemleri-Toyluk alt ölçekleri dışında diğer alt ölçeklerde (Davranım Bozuklukları, Kaygı-İ̇e Kapanma, Psikotik Davranış, Motor Gerilim) öğretmen ve anne-baba değerlendirmeleri arasındaki ilişkilerin anlamlı olduğunu; yüksek korelasyonların daha çok dışa yönelim ile ilgili problem alanlarında olduğunu; iki bilgi kaynağının değerlendirmeleri arasındaki ilişkilerin alan yazınla tutarlı şekilde düşük-orta düzey arasında değiştiğini ortaya koymuştur. Bulgular, alan yazın doğrultusunda tartışılmıştır.
\end{abstract}

Anahtar Sözcükler: Zihinsel engel, duygusal ve davranışsal problemler, problem davranış, öğretmen, anne-baba, Yenilenmiş Problem Davranış Kontrol Listesi

\section{GíRiş}

Zihinsel engelli çocukların problem davranışlarını belirlemeyi amaçlayan pek çok araştırma vardır (Örn., Acar, 2000; Acar ve Batu, 2001; Crinic, Hoffman, Gaze ve Edelbrock, 2004; Çiçekçi, 2000; Çiftçi ve Tabak, 1997; Decker; Nunn ve Koot, 2002; Kerker, Owens, Zigler ve Horwitz, 2004; Matson, Minshawi, Gonzales ve Mayville, 2006). Bu araştırmalardan elde edilen bulgulara bakıldığında, bu çocukların önemli duygusal ve

* Prof. Dr. (Emekli), Ankara Üniversitesi, Eğitim Bilimleri Fakültesi, Özel Eğitim Bölümü, kaner@education.ankara.edu.tr 
davranışsal sorunları olduğu, bu sorunların çocukların gelişimini olumsuz etkilediği, hem çocukların hem de ailelerinin yaşamlarını zorlaştırdığ 1 gözlenmektedir. Görev dışı davranışlar, aşırı hareketlilik, işlevsel olmayan tekrarlayıcı streotipik davranışlar, kendine ve başkalarına yönelik saldırgan davranışlar, yönergelere uymama, hırçınlık, dikkatsizlik, kaygı, ayrılık kaygısı, karamsarlık, içe kapanma, uygun olmayan konuşma, gece ve gündüz 1slatmaları, ağlama, sızlanma, yalan söyleme, başkalarıyla alay etme, başkalarına yönelik cinsel davranışlar zihin engellilerde en sık rastlanan problem davranışlardır (Acar ve Batu, 2000; Antshel, Phillips, Gordon, Barkley ve Faraone, 2006; Bhatia, Kabra ve Sarpa, 2005; Clark ve Wilson, 2003; Çiftçi ve İnce, 2002; Çiftçi ve Tabak, 2000: Dykens, 2000; Erbaş, Turan, Aslan ve Dunalp, baskıda; Freund ve Reis, 1991; Hashino ve ark., 1997; Dumley, 1986; Kerker ve ark., 2004; Özen, Çolak ve Acar, 2002; Polloway ve Epstein ve Cullinan, 1985; Rush, Bowman, Eidman, Toole ve Mortenson, 2004; Vatter, 1998; Vostanis ve ark., 1996; Yıkmış ve Ural, 2004). Zihin engelliler ayrıca sosyal becerilerinin yetersiz oluşuna bağlı iletişim ve etkileşim sorunları da göstermekte; anne-baba ya da akranlar tarafindan reddedilmekte ve toplumun etkin bir bireyi olarak işlevde bulunmada güçlükler yaşamaktadırlar. Engelli olmayan akranlarıyla kıyaslandığında da zihin engelli çocukların çok daha fazla duygusal ve davranışsal bozukluklar gösterdikleri (Coe ve ark., 1999; Costello ve Bouras, 2006; Cuskally ve Dads, 1992; Çiçekçi, 2000; Epstein, Cullinan ve Polloway, 1986; McGraww, Shaw ve Beckley, 2007; Polloway, Epstein ve Cullinan, 1985), tanılama ile ilgili bazı güçlükler olsa da \%10-42 arasında hafiften şiddetliye doğru psikiyatrik sorunların olduğu, \%1-24'ünde bu sorunların oldukça ciddi olduğu (Antshel, Phillips, Gordon, Barkley ve Faraone, 2006; Costello ve Bouras, 2006; Dykens, 2000; Emerson ve Hatton, 2007; Kerker ve ark., 2004; Masi, 1998; Rush ve ark., 2004; Singh, Sood, Sonenklar ve Ellis, 1991; Whitaker ve Read, 2006; Yaluğ ve Tufan, 2006) bildirilmektedir.

Zihin engelli çocuklarda duygusal ve davranışsal problemleri belirlemenin yollarından biri, dışsal değerlendiricilerin görüşlerine başvurmaktır. Anne-baba, öğretmen, çocuğun kendisi gibi farklı bilgi kaynakları, çocukla ilgili durumu bir bütün olarak görmemiz açısından önemlidir. İster zihin engelli, ister normal gelişim gösteren çocuklar olsun, tüm çocuklar farklı ortamlarda farklı davranışlar sergilerler. Bu nedenle, farklı kaynakların çocukların davranışlarına ilişkin bakış açıları, hoşgörü ya da katlanma düzeyleri, yaptıkları nedensel yüklemeler, başa çıkma şekilleri de farklılaşabilmektedir. 
Öğretmenler ve anne-babalar en çok kullanılan bilgi kaynaklarıdır. Her bilgi kaynağının kendine özgü güçlü ve zayıf tarafları vardır. Anne-babalar, çocuklarıyla doğumdan itibaren farklı ortamlarda yakın ilişki içinde oldukları için bilgilerine en sik başvurulan kişilerdir. Öğretmenler ise yapılandırılmış okul ortamında aynı yaş grubundaki çocukların akademik ve akademik olmayan davranışlarını gözleme olanağına sahip olmaları açısından önemli bilgi kaynaklarıdır.

Pek çok araştırma, engelli çocuklar için bu iki önemli bilgi kaynă̆ının değerlendirmeleri arasındaki tutarlılığı incelemiştir. Bulgular, tutarlılığın düşükten yüksek düzeye doğru değiştiğini (Blacher-Dixon ve Simeonsson, 1981; Coe ve ark., 1999; Clark ve Wilson, 2003; Dekker, Nunn, Einfeld, Tonge ve Koot, 2002; Dekker, Nunn, ve Koot, 2002; Freund ve Reis, 1991; Hundert, Morrison, Mahoney, Mundy ve Vernon, 1997; Keogh ve Bernheimer, 1998; Merrel ve Popinga, 1994; Treuting ve Elliott, 1997; Vostanis ve ark., 1996) ve tutarlılığın-tutarsızlığın çocuğun yaşı ve cinsiyeti (Smith, 2007), çocuğun problem davranışının özelliği ya da tanısı (Smith, 2007), bilgi kaynaklarının kişilik özellikleri, psikopatolojileri (Smith, 2007), engele yönelik tutumları (Keogh ve Bernheimer, 1998), ailenin sosyoekonomik düzeyi ve ortamın özellikleri ve talepleri (Keogh ve Bernheimer, 1998) gibi faktörlerden etkilendiğini göstermiştir. Anne ve baba gibi çocukla benzer ilişki içerisinde olan kaynakların görüşleri arasındaki tutarlılık ise, anne-baba ve öğretmen gibi farklı rolleri olan kaynaklara göre daha yüksektir (Cuskelly ve Dads, 1992; Keogh ve Bernheimer, 1998; Smith, 2007).

Mattison, Bagnato ve Strikler (1987), çocukların davranış problemlerini belirlerken aynı ölçeğin anne-baba ve öğretmen için farklı versiyonlarının kullanıldığını (örn., Dekker, Nunn ve Koot, 2002; Dekker ve ark., 2002) ve/veya benzer isimde ancak farklı maddelerden oluşan ölçeklerle/alt ölçeklerle farklı bilgi kaynaklarının görüşlerinin kıyaslandığını ifade etmektedirler. Bu durumda, bilgi kaynaklarının özdeş olmayan maddelere/alt ölçeklere verdikleri yanıtlar birbiri ile karşılaştırılmaktadır. Bu çalışmada, anne-babalar ve öğretmenler özdeş maddelere yanıt vermiş̧lerdir. Bu da, iki kaynağın değerlendirmelerinin doğrudan kıyaslanmasına olanak vermektedir.

Alan yazında, farklı bilgi kaynakları arasındaki tutarlılığın daha çok ölçek/alt ölçek düzeyinde incelendiğini (Örn., Aman, Tasse, Rojahn ve Hammer, 1996; Coe ve ark., 1999; Costenbader ve Kelly, 2007; Dekker ve ark., 2002; Handen, Feldman ve Honigman, 1987; Hundert ve ark., 1997; Merrel ve Popinga, 1994), tutarlılığı madde bazında inceleyen araştırmaların az olduğunu gözlemekteyiz. (Acar, 2000; Acar ve Batu, 2001; Cai, Kaiser ve 
Hancock, 20004; Clark ve Wilson, 2003; Çiftçi ve İnce, 2002; Çiftçi ve Tabak, 1997; Erbaş ve ark., baskıda; Handen ve ark., 1987). Bilgi kaynaklarının görüşlerini ölçme aracındaki her bir maddeye dayalı olarak kıyaslamak önemlidir. Bu kıyaslamayı yapan araştırmalar, eğitimcilerin, araştırmacıların ve ruh sağlığı uzmanlarının bu iki yaygın bilgi kaynağından elde edilen bilgileri birlikte değerlendirmelerini sağlayabilir; farklı bilgi kaynaklarının ev ve okul ortamında tutarlı olarak problem olduğunu bildirdikleri belirli davranışlara yönelik önleyici ve müdahale edici programların hazırlanmasına rehberlik edebilir (Cai ve ark., 20004). Bu çalışmada da bu amaca hizmet edeceği beklentisi ile engelli çocukların problem davranışlarının anne-baba ve öğretmen değerlendirmeleri arasındaki tutarlılıklar hem ölçek hem de madde bazında incelenmiştir.

\section{YÖNTEM}

\section{Araştırma Grubu.}

Araştırma grubunu, Ankara ili sınırları içerisinde bulunan özel özel eğitim kurumlarında eğitim alan zihinsel engelli çocukların anne-babaları ve öğretmenleri oluşturmaktadır. Ankara'da zihin engelli çocuklara eğitim veren bu kurumlardan tesadüfi olarak 20 eğitim kurumu seçilmiştir. Ancak 14 kurumdan geri dönüş sağlanabilmiştir. Bu kurumlarda görev yapan öğretmenlerin görüşlerine göre, çalışmada kullanılacak ölçme aracındaki maddeleri okuyabilecek ve anlayıp yanıt verebilecek anne-babalar belirlenmiştir. $\mathrm{Bu}$ anne-babaların yanı sıra aynı kurumda görev yapan tüm öğretmenler araştırma kapsamına alınmıştır.

Her öğretmenin, çok iyi tanıdığı beş öğrenciyi değerlendirmesi istenmiştir. $\mathrm{Bu}$ öğrencilerin de anne-babalarının değerlendirilmesine başvurulmuştur. $\mathrm{Bu}$ durumda, toplam 515 çocuğun öğretmenine ve annebabasına ulaşılmak hedeflenmiş olmakla birlikte, kullanılabilir durumda olan 206 veri kaynağı elde edilmiştir. Bu durumda, 206 anne-baba ve 206 öğretmenden olmak üzere toplam 412 kişiden veri toplanmıştır.

Değerlendirilen çocukların \%41.7'si kı $(n=86)$, \%58.3'ü erkektir $(n=120)$. Çocukların yaş ortalamaları ve standart sapmaları sırasıyla 11.37 ve 5.09'dur.

\section{Veri Toplama Aracı}

Yenilenmiş Problem Davranış Kontrol Listesi. Araştırmada, Quay ve Peterson (1996) tarafından geliştirilen, ülkemize uyarlama çalışması Kaner ve arkadaşları (Kaner, 1999, Kaner ve Çiçekçi-Uçak, 2000; Kaner ve 
Büyüköztürk, 2008) tarafından yapılan Yenilenmiş Problem Davranış Kontrol Listesi-YPDKL (Revised Problem Behavior Checklist-RPBC) kullanılmıştır.

5-17 yaş arasındaki çocukların ve ergenlerin öğretmenlerinden $(n=4818)$ ve anne-babalarından $(n=3849)$ olmak üzere, toplam 8667 kişiden elde edilen verilere Doğrulayıcı Faktör Analizi-DFA (Confirmatory Factor Analyisis-CFA) uygulanmıştır. Doğrulayıcı faktör analizi sonrasında elde edilen uyum indeks değerlerinin kabul edilir sınırlar içerisinde olduğu belirlenmiştir $(\mathrm{RMSEA}=0.085 ; \mathrm{RMR}=0.067$; GFI $=0.70 ;$ AGFI $=0.68$; $\mathrm{NFI}=0.97 ; \mathrm{NNFI}=0.97 ; \mathrm{CFI}=097 ; \mathrm{IFI}=0.97) . \mathrm{Bu}$ analiz sirasında bazı maddelerin elenmesi sonucunda YPDKL'ndeki madde sayıs 77 'den 62'ye inmiştir.

DFA analizi sonucunda, ölçeğin Türkçe formunda özgün yapıdaki 6 faktörün korunduğu gözlenmiştir: 1. Davranım Bozukluğu, 2. Toplumsallaşmış Saldırganlık, 3. Dikkat Problemleri-Toyluk, 4. Kayg1-İंe Kapanma, 5. Psikotik Davranış, 6. Motor Gerilim.

Ölçeğin benzer ölçek-aynılık geçerliğini belirlemek amacıyla 105 annebabaya ve 60 öğretmene YPDKL ile birlikte Yenilenmiş Conners Ebeveyn Dereceleme Ölçeği-Uzun Türkçe (YCEDÖ-UT) ve Yenilenmiş Conners Öğretmen Dereceleme Ölçeği-Uzun Türkçe (YCÖDÖ-UT) uygulanmıştır. YCEDÖ-UT ile YPDKL-T ve YCÖDÖ-UT ile YPDKL-T arasındaki korelasyonların sırasıyla $\quad 0.03-0.79$ ve $0.03-0.87$ arasında değiştiği bulunmuştur.

YPDKL'nin Cronbach Alfa iç tutarlılık katsayıları ve Spearman-Brown iki yarı güvenirlik katsayıları sırasıyla Davranım Bozukluğu için 0.93 ve 0.92, Toplumsallaşmış Saldırganlık için 0.89 ve 0.87, Dikkat ProblemleriToyluk için 0.89 ve 0.87 , Kayg1-İçe Kapanma için 0.84 ve 0.82 , Psikotik Davranış için 0.73 ve 0.73 , Motor Gerilim için 0.80 ve 0.83 'dür. YPDKL'ndeki maddeler üçlü likert tipi bir ölçek üzerinden dağerlendirilmektedir $(0=$ problem değil, $1=$ orta derecede problem, $2=$ ağır derecede problem). YPDKL'nden yüksek puan almak, problem davranışların yoğunluğunu ifade etmektedir.

\section{Verilerin Analizi.}

Anne-baba ve öğretmen değerlendirmeleri arasındaki ilişki hem alt ölçekler hem de madde düzeyinde Pearson Korelasyon Tekniği ile incelenmiştir. 


\section{BULGULAR}

Öğretmenlerin, anne-babaların ve tüm grubun alt ölçeklerden aldıkları puanların ortalamaları ve standart sapmaları Tablo 1'de verilmiştir.

Tablo1. Betimsel Istatistikler

\begin{tabular}{lllllll}
\hline \multirow{2}{*}{ Alt Ölçekler } & Öğretmen & \multicolumn{3}{c}{ Anne-Baba } & \multicolumn{2}{l}{ Tüm Grup } \\
\cline { 2 - 7 } & $\mathrm{x}$ & ss & $\mathrm{x}$ & ss & $\mathrm{x}$ & ss \\
\hline DB & 5.41 & 6.93 & 5.49 & 5.23 & 5.24 & 6.04 \\
TS & 0.96 & 2.64 & 1.07 & 2.42 & 0.87 & 2.26 \\
DP-T & 7.01 & 5.47 & 7.69 & 4.92 & 0.87 & 2.26 \\
K-İK & 4.34 & 4.02 & 3.75 & 2.98 & 3.73 & 3.50 \\
PD & 1.31 & 1.77 & 1.65 & 1.77 & 1.34 & 1.74 \\
MG & 1.41 & 1.78 & 1.95 & 1.92 & 1.70 & 1.93 \\
\hline
\end{tabular}

Tablo 1'de de gözlendiği gibi alt ölçeklerden alınan puanların ortalamaları öğretmenler için 0.96-7.01, anne-babalar için 1.07-7.69, tüm grup için ise 0.87-5.24 arasındadır. Puanların standart sapma değerleri ise aynı sırayla 1.77-6.93, 1.77-5.23 ve 1.74-6.04'dür.

Alt ölçeklere göre anne-babaların ve öğretmenlerin değerlendirmeleri arasındaki korelasyonlar Tablo 2'de verilmiştir.

Tablo 2. Alt Ölçeklere Göre Anne-Baba ve Öğretmen Değerlendirmeleri Arasındaki Korelasyonlar

\begin{tabular}{lcccccc}
\hline & DB & TS & DP-T & K-iK & PD & MG \\
\hline DB & $0.43^{* *}$ & & & & & \\
TS & & -0.02 & & & & \\
DP-T & & & 0.12 & $0.22^{*}$ & & \\
K-IK & & & & & $0.21^{*}$ & \\
PD & & & & & $0.40^{* *}$ \\
MG & & & & & & \\
\hline
\end{tabular}

$* \mathrm{p}<0.05 ; * * \mathrm{p}<0.01$

Tablo 2'de de gözlendiği gibi Toplumsallaşmış Saldırganlık ve Dikkat Problemleri-Toyluk alt ölçekleri arasındaki korelasyonların dışında diğer alt ölçekler arası korelasyonlar anlamlıdır. Anlamlı bulunan korelasyon katsayılarının ortalaması 0.26 'dır. bu durumda, iki bilgi kaynağının değerlendirmeleri arasındaki tutarlılığın düşük olduğu söylenebilir.

Maddelere göre anne-babaların ve öğretmenlerin değerlendirmeleri arasındaki korelasyonlar Tablo 3'de verilmiştir. 
Tablo 3. Maddelere Göre Anne-Baba ve Öğretmen Değerlendirmeleri Arasındaki

Korelasyonlar

\begin{tabular}{|c|c|c|c|c|c|c|c|c|c|c|c|}
\hline \multicolumn{12}{|c|}{ Alt Ölçekler } \\
\hline \multirow{2}{*}{$\begin{array}{l}\text { DB } \\
\text { Mad. } \\
\text { No. }\end{array}$} & \multirow[b]{2}{*}{$\mathbf{r}$} & \multirow{2}{*}{$\begin{array}{l}\text { TS } \\
\text { Mad. } \\
\text { No. }\end{array}$} & \multirow[b]{2}{*}{$\mathbf{r}$} & \multicolumn{2}{|c|}{ DP-T } & \multicolumn{2}{|c|}{ K-İK } & \multicolumn{2}{|l|}{ PD } & \multicolumn{2}{|l|}{ MG } \\
\hline & & & & $\begin{array}{l}\text { Mad. } \\
\text { No. }\end{array}$ & $\mathbf{r}$ & $\begin{array}{l}\text { Mad. } \\
\text { No. }\end{array}$ & $\mathbf{r}$ & $\begin{array}{l}\text { Mad. } \\
\text { No. }\end{array}$ & $\mathbf{r}$ & $\begin{array}{l}\text { Mad. } \\
\text { No. }\end{array}$ & $\mathbf{r}$ \\
\hline 2 & $0.24 * *$ & 3 & $0.37 * *$ & 10 & $0.26^{* *}$ & 4 & $0.28 * *$ & 9 & $0.28 * *$ & 1 & $0.29 * *$ \\
\hline 5 & $0.35 * *$ & 7 & $0.38 * *$ & 12 & $0.18^{*}$ & 6 & $0.39 * *$ & 13 & $0.18^{*}$ & 23 & $0.37 * *$ \\
\hline 14 & $0.25 * *$ & 8 & -0.02 & 22 & 0.10 & 11 & $0.26 * *$ & 29 & $0.21 * *$ & 58 & $0.30^{* *}$ \\
\hline 16 & $0.30 * *$ & 15 & 0.01 & 24 & $0.18^{*}$ & 18 & $0.24 * *$ & 60 & $0.17^{*}$ & & \\
\hline 20 & $0.36^{* *}$ & 17 & $0.30 * *$ & 27 & 0.12 & 19 & $0.33^{* *}$ & & & & \\
\hline 25 & $0.25 * *$ & 35 & -0.01 & 28 & 0.11 & 21 & 0.08 & & & & \\
\hline 26 & $0.28 * *$ & 38 & $0.21^{*}$ & 34 & $0.21 * *$ & 45 & -0.01 & & & & \\
\hline 30 & $0.16^{*}$ & 39 & 0.09 & 35 & $0.22 * *$ & 51 & 0.04 & & & & \\
\hline 31 & $0.19^{*}$ & 42 & $0.26^{* *}$ & 41 & $0.18^{*}$ & 59 & 0.15 & & & & \\
\hline 32 & $0.28 * *$ & 43 & -0.02 & 47 & 0.11 & & & & & & \\
\hline 36 & $0.21 * *$ & 44 & 0.14 & 48 & $0.28 * *$ & & & & & & \\
\hline 37 & $0.24 * *$ & 50 & 0.09 & 49 & 0.13 & & & & & & \\
\hline 40 & 0.05 & 53 & -0.02 & 54 & 0.13 & & & & & & \\
\hline 46 & $0.21 * *$ & 61 & $0.28 * *$ & & & & & & & & \\
\hline 52 & 0.12 & 62 & $0.42 * *$ & & & & & & & & \\
\hline 55 & $0.33 * *$ & & & & & & & & & & \\
\hline 56 & $0.25^{* *}$ & & & & & & & & & & \\
\hline 57 & $0.19^{*}$ & & & & & & & & & & \\
\hline
\end{tabular}

${ }^{*} \mathrm{p}<0.05 ; * * \mathrm{p}<0.01$

Tablo 3'de de gözlendiği gibi Psikotik Davranış ve Motor Gerilim alt ölçeğinin tüm maddelerinde anne-babaların ve öğretmenlerin değerlendirmeleri arasındaki ilişkiler anlamlıdır. Anlamlı korelasyon katsayılarının ortalamaları 0.27 'dir.

Davranım Bozukluğu alt ölçeği için elde edilen değerler incelendiğinde, iki maddenin (40. ve 52. maddeler) dışında anne-babaların ve öğretmenlerin değerlendirmelerinin tutarlı olduğunu görmekteyiz.

Toplumsallaşmış Saldırganlık, Dikkat Problemleri-Toyluk ve Kaygı-İçe Kapanma alt ölçeklerinde ise farklı bir durum gözlenmektedir. Onbeş maddelik Toplumsallaşmış Saldırganlık alt ölçeğinde sadece yedi madde için iki bilgi kaynağı benzer görüş bildirmişlerdir. On üç maddelik Dikkat Problemleri-Toyluk alt ölçeğinde de yedi maddeye anne-babalar ve öğretmenler benzer görüşler bildirmişlerdir. Kaygı-İçe Kapanma alt 
ölçeğinde ise dokuz maddenin beşinde anne-baba ile öğretmen tutarlıl1ı̆ı sağlanabilmiştir. .

Alt ölçeklere göre anlamlı bulunan maddeler arası korelasyonların ortalamaları sirasiyla $0.26,0.32,0.21,0.30,0.21$ ve 0.32 'dir. $\mathrm{Bu}$ korelasyonlar, anne-baba ve öğretmen görüşleri arasındaki tutarlılığın düşük olduğunu göstermektedir.

Alt ölçeklerde yer alan maddelerin ortalamaları hesaplanmış ve en yüksek ortalama puana sahip maddeler sıralanmıştır. Puan ortalamalarına göre ilk 5 sırada yer alan problem davranışlar belirlenmiş ve bu maddelerin ortalamaları ve standart sapmaları Tablo 4'de verilmiştir.

Tablo 4. Illk Beş Sırada Bildirilen Problem Davranışların Ortalamaları ve Standart Sapmalart

\begin{tabular}{|c|c|c|c|c|c|}
\hline Öğretmen & & & Anne-Baba & & \\
\hline Madde No. & $\mathbf{x}$ & SS & Madde No. & $\mathbf{x}$ & SS \\
\hline $\begin{array}{l}\text { 10. Dikkati kısa sürelidir; } \\
\text { konsantrasyonu zayıftır }\end{array}$ & 1.13 & 1.47 & $\begin{array}{l}\text { 10. Dikkati k1sa sürelidir; } \\
\text { konsantrasyonu zayıftır }\end{array}$ & 1.08 & 0.65 \\
\hline $\begin{array}{l}\text { 24. Dikkati başka tarafa } \\
\text { çekilebilir; ilgisi elindeki } \\
\text { işten başka yöne kolay } \\
\text { çevrilebilir }\end{array}$ & 0.89 & 0.72 & $\begin{array}{l}\text { 24. Dikkati başka tarafa } \\
\text { çekilebilir; ilgisi elindeki } \\
\text { işten başka yöne kolay } \\
\text { çevrilebilir }\end{array}$ & 0.92 & 0.70 \\
\hline $\begin{array}{l}\text { 35. Kendi başına bir iş } \\
\text { yapamaz; sürekli yardıma } \\
\text { ve ilgiye ihtiyacı vardır }\end{array}$ & 0.76 & 0.78 & $\begin{array}{l}\text { 18. Aşırı duyarlıdır; } \\
\text { duyguları çok kolay incinir }\end{array}$ & 0.80 & 0.72 \\
\hline 11. Kendine güveni yoktur & 0.72 & 0.70 & $\begin{array}{l}\text { 35. Kendi başına bir iş } \\
\text { yapamaz; sürekli yardıma } \\
\text { ve ilgiye ihtiyacı vardır }\end{array}$ & 0.77 & 0.72 \\
\hline $\begin{array}{l}\text { 18. Aşırı } \quad \text { duyarlıdır; } \\
\text { duyguları çok kolay } \\
\text { incinir }\end{array}$ & 0.67 & 0.65 & $\begin{array}{l}\text { 32. Israrcıdır, dediğim } \\
\text { dediktir; } \\
\text { anlamaz }\end{array}$ & 0.75 & 0.73 \\
\hline
\end{tabular}

Tablo 4'de de gözlendiği gibi hem öğretmenler hem de anne-babalar için dikkat eksikliğiyle ilgili problemler ilk beş sırada yer almaktadır. Ayrıca, öğretmenler için kendine güvensizlik ve aşırı duyarlılık, annebabalar için aşırı duyarlık ve inatçılık sorunları da ilk beş içinde yer almıştır. Tablo 3'e geri dönüp baktığımızda, ortak olan maddeler arasındaki korelasyonların anlamlı olduğunu gözlenmektedir. Bu sonuçlar aşağıda verilmiştir (Bkn. Tablo 5). 
Tablo 5. Ilk Siralarda yer Alan Ortak Maddeler Arası Korelasyonlar

\begin{tabular}{|c|c|c|c|c|c|c|c|}
\hline $\begin{array}{l}\text { Alt } \\
\text { Ölçek }\end{array}$ & $\begin{array}{l}\text { Madde } \\
\text { no. }\end{array}$ & 10 & 24 & 35 & 18 & 11 & 32 \\
\hline DP-T & 10 & $0.26 * *$ & & & & & \\
\hline DP-T & 24 & & $18^{*}$ & & & & \\
\hline DP-T & 35 & & & $0.22 *$ & & & \\
\hline K-İK & 18 & & & & $0.24 *$ & & \\
\hline KİK & $11 * * *$ & & & & & $0.26 * *$ & \\
\hline DB & $32 * * * *$ & & & & & & $0.28 * *$ \\
\hline
\end{tabular}

\section{TARTIŞMA ve SONUÇ}

Bu çalışmada, hem alt ölçek hem de madde düzeyinde olmak üzere öğretmenlerin ve anne-babaların çocukların problem davranışlarını değerlendirmeleri arasındaki ilişkiler incelenmiştir.

Alt ölçekler düzeyinde yapılan kıyaslamalar, sonucunda Toplumsallaşmış Saldırganlık ve Dikkat Problemleri-Toyluk dışındaki diğer problem alanlarında (Davranım Bozukluğu, Kaygi-İçe Kapanma, Psikotik Davranış ve Motor Gerilim) anne-babalar ile öğretmenler arasında görüş birliği olduğu gözlenmiştir.

Zihin engelliler alan yazınında, anne-baba ve öğretmen değerlendirmelerini kıyaslayan araştırmaların birbiriyle çelişen sonuçlar verdiği görülmektedir. Örneğin bazı çalışmalar, bu iki bilgi kaynağının değerlendirmelerinde kullanılan ölçme araçlarının hemen tüm alt boyutlarında orta ya da yüksek düzeyde anlamlı ilişki verirken (örneğin, Aman ve ark., 1996; Blacher ve Simeonsson, 1981; Clark ve Wilson, 2003; Dekker, Nunn, Einfeld, Tonge ve Koot, 2002; Dekker ve ark., 2002; Handen ve ark., 1987; Hundert ve ark., 1997; Keogh ve Bernheimer, 1998; VanVorhis ve ark., 1996), bazıları da anne-baba ve öğretmen değerlendirmelerinin birbirinden oldukça farklı olduğunu, dolayısıyla aralarındaki korelasyonların düşük olduğunu ortaya koymuştur (Coe ve ark., 1999; Costenbader ve Keller,1990; Freund ve Reis, 1991; Liepman ve Ort, 1980; Merrel ve Popinga, 1994; Treuting ve Elliott, 1997; Vostanis ve ark., 1996). Bu çalışmadan elde edilen alt ölçekler arasındaki anlamlı korelasyon katsayıları 0.21-0.79 arasında değişen değerleriyle pek çok çalışma ile tutarl1lık göstermektedir. 
Alt ölçekler arası korelasyon katsayıları incelendiğinde, yüksek tutarlılık katsayılarının dışa yönelim problemlerinde, düşük korelasyon değerlerinin ise içe yönelim sorunlarında olduğu gözlenmektedir. En yüksek tutarlılık katsayılarının Davranım Bozukluğu (0.43) ve Motor Gerilim (0.40) alt ölçeklerinde, daha sonra da Kayg1-Içe Kapanma (0.22) ve Psikotik Davranış (0.21) alt ölçeklerinde olduğunu görmekteyiz. Her ne kadar çelişkili sonuçlar elde edilse de, pek çok araştırma, görüş tutarlılı̆̆ının, içe yönelim sorunlarına göre daha kolay gözlenebilir olmaları nedeniyle dışa yönelim sorunlarında olduğunu ortaya koymaktadır (De Los Reyezs ve Kazdin, 2005). Smith (2007), dışsal değerlendiricilerin, içe yönelim belirtilerini dışa yönelim belirtilerine göre daha az doğru kestirebildiklerini bildirmektedir. Vostanis ve arkadaşları da (1996), en yüksek anne-baba ve öğretmen tutarlılığının hırçınlık (0.61), hiperaktivite $(0.58)$ boyutlarında olduğunu, bunları uygun olmayan konuşmanın $(0.40)$, içe kapanmanın $(0.32)$ ve streotipik davranışın izlediğini bildirmiştir. Bir diğer çalışma da benzer sonuçlar vermektedir (Freund ve Reis, 1991): en yüksek korelasyon katsayıları sırasıyla hırçınlık (0.49), hiperaktivite (0.47), streotipi $(0.45)$ ve uygun olmayan konuşma (0.39) alt ölçeklerinde bulunmuştur. Handen ve arkadaşları da (1987) öfke nöbetleri, başkalarına vurma ve nesneleri firlatma gibi saldırgan davranışlarda öğretmen ve anne-baba tutarlılığının \%61-63 gibi yüksek olduğunu bildirmişlerdir. Benzer durum, madde düzeyindeki korelasyonlarda da belirlenmiştir. Anne-baba ve öğretmen gibi dişsal değerlendiriciler, içe yönelim sorunlarını bireylerin kendileri kadar iyi kestiremeyebilmektedirler. $\mathrm{Bu}$ nedenle, dışsal değerlendiriciler kadar çocuğun kendisinin de görüşlerine başvurmak ya da içe yönelim ile ilgili problem davranışları farklı bağlamlarda incelemek yerinde olabilir.

$\mathrm{Bu}$ bulguların yanı sıra, alan yazında anne-baba ve öğretmen değerlendirmeleri arasındaki korelasyonların hem içe hem de dışa yönelim sorunlarında manidar olduğuna işaret eden sonuçlara da ulaşılmıştır (Aman ve ark., 1996; Costenbader ve Kelly, 1990; Dekker ve ark., 2002; Vostanis ve ark., 1996). Birbiriyle çelişen bu sonuçlar, dişsal değerlendiricilerin, çocukların bazı problem alanlarını benzer şekilde algıladıklarını ancak, bazı problem alanlarında ise farklı görüşlere sahip olduklarına işaret etmektedir.

Zihin engelli çocuklarda Quay ve Peterson'un Yenilenmiş Problem Davranış Kontrol Listesi'ni kullanan, bizim çalışmamıza benzer tek bir çalışmaya ulaşılabilmiştir. Coe ve arkadaşlarının (1996) Down sendromlu çocuklar ile yaptıkları çalışmada, bu makalede sunulan bulgularımızdan farklı olarak tüm alt ölçeklerde iki bilgi kaynağı arasındaki korelasyonların anlamlı olduğu, korelasyon katsayıları ortalamalarının (0.34) ise bu çalışmadan elde edilen ortalamaya (0.26) yakın olduğu bulunmuştur. 
En yüksek korelasyon katsayısı Davranım bozukluğu alt ölçeğinden elde edilmiştir $(0.43, \mathrm{p}<0.001)$. Bu bulgu, genel olarak alan yazın bulguları ile tutarlıdır. Bir davranış, örneğin 'başkalarıyla alay eder-kavga eder-aşırı hareketlidir' gibi belirgin, gözlenebilir ise anne-babanın ve öğretmenin bu davranıştan aynı şeyi anlaması beklenir. Buna karşın 'kendini değersiz hisseder-başarılı olamayacağı duygusu vardır' gibi daha az belirgin ya da içe yönelim gibi dikkati daha az çeken davranışlar, bilgi kaynaklarının görüşlerindeki tutarlılığı azaltabilir. Bu alt ölçekteki maddelerin çoğu, yukarıdaki örnektekine benzer olduğu için elde edilen katsayının buna bağlı olarak yüksek olduğu düşünülmektedir. Zihin engelli çocuklarda öfke nöbetleri, başkalarına vurma, nesneleri firlatma, saç çekme, başkalarını 1sırma, başkalarıyla alay etme gibi saldırgan davranışlar ve yönergeleri izlememe gibi dışa yönelim problemlerinde, anne-babaların ve öğretmenlerin görüşleri genellikle birbirleriyle uyumlu görünmektedir (Coe ve ark., 1999; Fee, Matson, Moore ve Benavidez, 1993; Gumley, 1986; Handen ve ark., 1987).

Zihin engelli bireylerde saldırgan, dürtüsel, kendine zarar verici, streotipik davranışlarla ve yeme bozukluklarıyla kendini gösteren davranış bozuklukları oldukça yaygındır. Araştırmalar, davranım bozukluklarının zihin engellilerde \%40-59 arasında yaygın olduğunu göstermektedir (Acar ve Batu, 2001; Bhatia ve ark., 2005; Crnic ve ark., 2004; Çiftçi ve İnce, 2002; Fee, 1993; Fee ve ark., 1993; Kerker ve ark., 2004: Masi, 1998; Özen ve ark., 2002; Vatter, 1998). Bazı çalışmalarda da, aşırı hareketlilik ile ilgili maddelerden oluşan Motor Gerilim alt ölçeğine ilişkin bulgumuzda olduğu gibi anne-baba ve öğretmenlerin aşırı hareketlilik ile ilgili değerlendirmeleri anlamlı ilişki vermektedir (Freund ve Reis, 1991; Masi, 1998; Merrel ve Popinga, 1994; Vostanis ve ark.,1996). Aşırı hareketlilik zihin engellilerde yaygın olarak görülen bir diğer bozukluktur (Bhatia ve ark., 2005; Fee, 1993; Crnic ve ark., 2004; Masi, 1998).

Anne-baba ve öğretmen görüşleri arasında anlamlı ilişki veren bir diğer alt ölçek ise Kaygı-Içe Kapanmadır. Alan yazın, özellikle kaygı ve depresyon gibi içe yönelim sorunlarında, dışsal değerlendiriciler arası tutarlılığın genel olarak düşükten orta düzeye doğru değiştiğini göstermektedir (Akt., De Los Reyezs ve Kazdin, 2055). Bu çalışmadan elde edilen korelasyon katsayısı da (0.22) bu yöndeki bulguları desteklemektedir. Vostanis ve arkadaşları (1996) özel eğitim ve kaynaştırma sınıflarında eğitim alan engelli öğrencilerin içe kapanma alt ölçeğinde öğretmen-anne-baba değerlendirmeleri arasında yüksek ilişki bulmuşlardır. Coe ve arkadaşları da (1999) benzer bulgular elde etmişlerdir. Freund ve Reis (1991) ve Merrel ve Popinga (1994) ise bu bulgulardan farklı olarak içe kapanma ile ilgili 
problemlerin anne-babalar ve öğretmenler tarafından farkl1 değerlendirildiğini, iki bilgi kaynağının değerlendirmeleri arasında anlamlı ilişki olmadığını bildirmişler ve bu durumu içe kapanmayla ilgili davranışların değerlendirilmesinin daha zor olmasına bağlamışlardır.

Psikotik Davranış alt ölçeğinde de anne-baba-öğretmen değerlendirmeleri arasında anlamlı ilişki bulunmuştur. $\mathrm{Bu}$ alt ölçekteki maddeler incelendiğinde (Konuşması tutarsızdır; söyledikleri bir anlam ifade etmez- Garip, mantıksız düşünceler ifade eder- Hayali şeyleri sanki gerçekmiş gibi anlatır; gerçeği, hayalden ayıramaz), maddelerin düşünce bozukluğu ve uygun olmayan konuşma sorunlarını içerdiği gözlenmektedir. $\mathrm{Bu}$ sorunlar, dikkati hemen çekmeleri nedeniyle alan yazında da farklı bilgi kaynakları tarafindan en çok dile getirilen sorunlar arasında yer almaktadır (Coe ve ark., 1999; Erbaş ve ark., baskıda). Bu nedenle, anne-baba ve öğretmenlerin üzerinde kolayca aynı fikirde olabilecekleri davranışlar olarak değerlendirilebilirler. Zihin engelli çocuk ve ergenlerde psikotik bozuklukların \%1-7 arasında olduğu gözlenmektedir (Coe ve ark., 1999; Yaluğ ve Tufan, 2005).

Zihin engelli çocukların davranışlarının değerlendirilmesinde Toplumsallaşmış Saldırganlık ve Dikkat Problemleri-Toyluk alt ölçeklerinde iki bilgi kaynağı arasında ilişki bulunmamıştır. Toplumsallaşmış Saldırganlık alt ölçeğini oluşturan maddeler incelendiğinde, bu alt ölçekteki problem davranışların, zihinsel engelli çocuklar tarafindan daha az sergilendiğini, bu alt ölçek maddelerindeki davranışların (Örn., Suçlu arkadaşlarına sadıktır; Başkalarıyla birlikte uyuşturucu kullanır; Ahlaki değerlere ve yasalara saygı duymadığını açıkça itiraf eder; Arkadaşlarını korumak için yalan söyler) daha çok her iki bilgi kaynağının çocuklarla etkileşimde bulunma, izleme ve denetleme olanaklarının az olduğu ortamlarda ortaya çıktığını söyleyebiliriz. Bu nedenle, anne-babalar ve öğretmenler bu davranışları gözleyebildikleri ya da tahmin edebildikleri oranda değerlendirmiş olabilirler. Coe ve arkadaşları (1991) ise farklı bir sonuca ulaşmışlar ve bu alt ölçekte iki kaynak arasında anlamlı ilişki bulmuşlardır.

Alan yazında zihinsel yetersizliği olan bireylerin yaygın olarak bildirilen problemlerinden biri de dikkat eksikliğidir (Coe ve ark., 1999; Dekker ve ark., 2002; Fee ve ark., 1993; Poloway ve ark., 1985; Vostanis ve ark., 1996). Bu çalışmada ise Dikkat problemleri-Toyluk alt ölçeğinden anlamlı korelasyon elde edilmemiştir. Genelde, öğretmenlerin özellikle dikkat eksikliği ile ilgili problemlerde anne-babalara göre daha iyi kaynak oldukları ifade edilmektedir (Loeber, Green ve Lahey, 1990: Akt., Helton ve ark., 2005). Bu alt ölçekteki davranışların (Örneğin, Dikkati kısa sürelidir ve 
zayıftır; yönergeleri izlemekte güçlük çeker; okul ödevleri karmaşıktır, düzensizdir, baştan savmadır), özellikle yapılandırılmış okul ortamının taleplerini karşılamada sorun yaratan davranışlar olması ve bu nedenle de okul ortamında daha çok gözlenebilir olması nedeniyle anne-babalardan çok öğretmenlerin dikkatini çekmesi beklenebilir. Ayrıca, bu alt ölçekte dikkat eksikliğinin yanı sıra yaşına uygun olmayan davranışlar göstermeyle ilgili "toyluk" boyutunun da bulunması sonuçları etkiliyor olabilir. Ya da aynı davranışlara farklı kaynaklar farklı yüklemelerde bulunuyor olabilirler. Bazı araştırmalarda ise bu çalışmadan elde edilen bulgunun aksi yönde bir sonuç elde edildiği gözlenmektedir (Coe ve ark.,1991; Merrel ve Popinga, 1994; Vostanis ve ark., 1996).

$\mathrm{Bu}$ bulgu, yetişkinlerin ev ve okul gibi belirli ortamlarda yaptıkları davranışsal yüklemelerin farklı olduğunu göstermektedir. Bir diğer deyişle, farklı ortamlarda farklı rolleri yerine getiren anne-babaların ve öğretmenlerin durumsal taleplerinin, çocukların davranışlarına ilişkin değerlendirmelerini etkilediğini göstermektedir. İçinde bulunulan bağlam, bilgi kaynaklarından elde edilen değerlendirmelerin farklılaşmasına yol açmaktadır. Ayrıca, annebaba ya da öğretmen değerlendirmeleri, çocuğun gerçek davranışından daha çok onların çocuğu ne kadar yakından tanıdıklarına, değerlendirmenin amacına ve çocuğu hangi koşullar altında gözlediklerine bağlı algılarına dayanmaktadır. Yani her bilgi kaynağı, farklı sosyal sistemler içerisinde, farklı duygusal, davranışsal ve bilişsel özellikler doğrultusunda kendine özgü bakış açılarını yansıtmaktadır (Cuskell ve Dads, 1992; Smith, 2007). Bu durumda, değerlendirmeciler arasında görüş birliğinin yüksek olmasını beklemek de gerçekçi bir beklenti gibi görünmemektedir. Bu araştırmada, alt ölçekler arasındaki ortalama korelasyon katsayısının yaklaşık 0.20 civarında olması da bunu doğrulamaktadır.

Aslında, ne anne-babaların ne de öğretmenlerin değerlendirmeleri geçersiz değildir. Her biri kendi bakış açısından çocuğun davranışını gözlemlemektedir (Smith, 2007). Bu da iki değerlendirme arasındaki korelasyonu düşürmekte ya da yükseltmektedir. $\mathrm{Bu}$ nedenle, her bilgi kaynağının tüm problem davranışlar için eşit derecede geçerli değerlendirme yapacaklarını beklemek yerine hangi bilgi kaynağının hangi koşullar altında hangi davranışlar için daha geçerli bir değerlendirme yapacağını belirlemek daha uygun olacaktır (Smith, 2007).

Madde düzeyinde iki bilgi kaynağının değerlendirmeleri arasındaki tutarlılık, hem maddeler arası korelasyonlar hem de en yüksek ortalamaya sahip ilk beş davranış açısından da incelenmiştir. 
Anne-baba ve öğretmen değerlendirmeleri maddeler arası korelasyonlar açısından incelendiğinde toplam 62 maddenin yarıdan fazlasında (42 maddede) anlamlı korelasyonlar elde edilmiştir. Alt ölçeklere göre maddeler arası korelasyonlar 0.21-0.32 arasında değişmektedir. Ölçek düzeyinde olduğu gibi madde düzeyinde de anne-baba ve öğretmen derecelemeleri arasında düşük korelasyon saptanmıştır. Bu sonuçlar, yine anne-babalar ile öğretmenlerin çocukları farklı değerlendirdiklerini göstermekte ve madde düzeyinde anne-baba ve öğretmen değerlendirmeleri arasında düşük korelasyon belirlendiğini gösteren bulgular ile benzerlik göstermektedir (Cai ve ark., 2004; Gagnon, Vitaro, ve Trembley, 1992; Statake ve ark., 2003). Anlamlı korelasyon veren 42 maddenin onaltıs1 Davranım Bozukluğu, yedisi Toplumsallaşmış Saldırganlık, yedisi Dikkat Problemleri-Toyluk, beşi Kaygı-İçe Kapanma, dördü Psikotik Davranış ve üçü de Motor Gerilim alt ölçeklerine ait olduğu görülmektedir. Bu maddelerin 30'unun dişa yönelim, yedisinin ise içe yönelim, yedisinin de dikkat ile ilgili problem davranışlar olduğu ve korelasyon katsayılarının da alan yazın ile (Cai ve ark., 2004; Gagnon ve ark., 1992; Statake ve ark., 2003) tutarlı şekilde 0.16 ile 0.42 arasında değiştiği, ortalama korelasyon değerinin 0.26 olduğu ve düşükten ortaya doğru olduğu dikkati çekmektedir. Davranım Bozukluğu alt ölçeğinin iki maddesi dışında tüm maddelerinin, Psikotik Davranış ve Motor Gerilim alt ölçeklerinin tüm maddelerinde annebaba ve öğretmen değerlendirmeleri arasındaki ilişkilerinin anlamlı olması, her iki bilgi kaynağının da gözlenebilir dışa yönelim davranışlarını, içe yönelim davranışlarına göre daha çok benzer şekilde değerlendirdiklerini göstermektedir. Her ne kadar madde düzeyinde kıyaslama yapan araştırma sayıs1 sınırlı olsa da bu sonuç, var olan alan yazını desteklemektedir. Örneğin, Verhultz ve Akkerhuis (1989), 4-12 yaşındaki çocuklara ilişkin öğretmen ve anne-baba ve öğretmen değerlendirmeleri arasındaki korelasyonların madde düzeyinde 0.00 ile 0.58 arasında düşükten ortaya doğru değiştiğini, yüksek korelasyonların konuşma sorunları, kilo ve davranım bozuklukları gibi gözlenebilir belirtilerle ilgili olduğunu bildirmişlerdir. Gagnon ve arkadaşları'da (1992) duygulanım (affektif) problemlerinde korelasyon katsayılarının okul öncesi çocuklarında benzer şekilde düşükten ortaya kadar değiştiğini bulmuşlardır. Clark ve Wilson'un (2003) çalışmasında 60 maddenin \%75'inde tutarlılı̆̆ın yüksek olduğu ve bu tutarlılığın hem içe yönelim hem de dışa yönelim sorunlarında gözlendiği, Cai ve arkadaşlarının (2003) çalışmalarında ise düşük ilişki olduğu gözlenmektedir.

Problem davranışların sıklığına ilişkin madde düzeyinde yapılan analizde, hem anne-baba hem de öğretmen değerlendirmesinde maddeler 
puan ortalamalarına göre sıralanmış ve ilk beş sırada yer alan maddeler arasındaki ilişkiler incelenmiştir. Öğretmen ve anne babalar için ilk sıralarda yer alan ortak maddelerin dikkat eksikliğiyle ilgili olduğu belirlenmiştir. $\mathrm{Bu}$ maddeler arasındaki korelasyonlar da anlamlıdır.

Anne-babaların ve öğretmenlerin problem davranışların sıklığına ilişkin bildirimleri, iki bilgi kaynağının görüşleri arasındaki tutarlılığa ilişkin alt ölçek ve madde düzeyindeki korelasyon bulgularından farklı görünmektedir. Her iki grup da, çocukların en çok dikkat eksikliği ve toyluk ile ilgili sorunlara sahip oldukları görüşündedirler. Bunu, kaygı ve içe kapanma ile ilgili sorunlar izlemektedir. Bir diğer deyişle, dikkat eksikliği, yaşına uygun olmayan davranışlar tıpkı diğer araştırmalarda olduğu gibi zihin engellilerin en yaygın sorunları arasındadır (Antshel ve ark., 2006; Başal ve Taner, 2007; Bhatia ve ark., 2005; Clark ve Wilson, 2003; Coe ve ark., 1999; Çiftçi ve İnce, 2002; Dyken, 2000; Erbaş ve ark., baskıda; Freund ve Reis, 1991; Hashino ve ark., 1997; Dumley, 1986; Kerker ve ark., 2004; McGraw ve ark., 2007; Polloway ve ark., 1985; Rush ve ark., 2004; Vatter, 1998; Vostanis ve ark., 1996; Yıkmış ve Ural, 2004).

Dikkat eksikliği, öğrencilerin akademik ve akademik olmayan pek çok etkinliğe katılımlarını ve öğrenmelerini, başkalarıyla etkileşimlerini ve eğitim ortamını olumsuz etkilediği için öğretmenlerin en çok yakındıkları sorunlardandır. $\mathrm{Bu}$ çalışmada, anne-babalar da öğretmenler gibi aynı sorunların çocuklarında yaygın olduğu görüşündedirler. Dikkat eksikliği ile ilgili bu maddeler incelendiğinde (Örneğin, Dikkati kısa sürelidir; konsantrasyonu zayıftır; dikkati başka tarafa çekilebilir; ilgisi elindeki işten başka yöne kolay çevrilebilir), içinde bulunulan ortam ve bu ortama ilişkin beklentiler farklı bile olsa, dikkat eksikliğinin zihin engelli çocukların gelişimlerini olumsuz etkileyen önemli ve dikkati çeken bir sorun olduğunu göstermektedir.

Zihin engelli çocuklarda en çok gözlenen diğer davranışlar Kaygı-İçe kapanma ile ilgili sorunlardır (Örneğin, Kendine güveni yoktur; Aşırı duyarlıdır, duyguları çok kolay incinir). Anne-babalar, ayrıca Davranım Bozukluğu alt ölçeğinde yer alan bir davranışı da (Israrcıdır, dediğim dediktir; "hayır"dan anlamaz) çocuklarında sıklıkla gördüklerini bildirmişlerdir. Bu davranışlar, farklı bilgi kaynakları tarafından zihin engelli çocuklarda gözlenen diğer problem alanlarındandır (Bhatia ve ark., 2005; Clark ve Wilson, 2003; Çiftçi ve İnce, 2002; Dyken, 2000; Freund ve Reis, 1991; Hashino ve ark., 1997; Dumley, 1986; Kerker ve ark., 2004; Polloway ve ark., 1985; Rush ve ark., 2004; Vatter, 1998; Vostanis ve ark., 1996). Ancak, problem davranışları sıralamada yüksek tutarlılığın olması, annebabalar ile öğretmenlerin çocukta problem davranışlar olduğu konusunda 
anlaştıkları şeklinde değerlendirilmemesi de gerekir. Bu daha çok, iki bilgi kaynağı için de belirli davranışların diğerlerine göre daha yaygın olduğunu işaret etmektedir (Cai ve ark., 2004). Farklı değerlendiriciler arasındaki tutarlılığın araştırmalara göre değişmesi, elde edilen bulguların geçerli olmadığını ya da gerçeği yansıtmadığını göstermez. Bu, daha çok aynı davranışların farklı algılanıyor olmasını ve çocuğa ilişkin beklentilerin ve onunla kurulan ilişkilerin farklı olmasını işaret ediyor olabilir. Ayrıca, problem davranışlar görülme sıklığı açısından sıralandığında, dışsal değerlendiricilerin görüş birliğinin arttığ 1 da bilinmektedir (Cai ve ark., 2004; Gagnon ve ark., 1992).

Aman ve arkadaşları (1996), zihinsel engelli çocukların problem davranışlarını belirlemek amacıyla geliştirilmiş ve anne-baba ve öğretmen formları olan bir ölçme aracıyla (Aberrant Behavior Checklist) bu iki bilgi kaynağının değerlendirmeleri arasındaki ilişkiyi incelemişlerdir. Aman ve arkadaşları bu çalışmada, hem dişa yönelim hem de içe yönelim problemleri için anlamlı ilişkiler bulmuşlardır. Bu bulgu, zihin engellilere yönelik ölçme araçları kullanılarak bilgi kaynakları arasındaki tutarlılığın incelenmesi gerektiğini işaret ediyor görünmektedir. Freund ve Reiss'in (1991) çalışmaları da bu görüşü doğrular niteliktedir. Freund ve Reiss (1991), zihinsel engelli çocuklarda psikiyatrik semptomları belirlemek amacıyla geliştirilmiş bir ölçme aracı kullanmışlar ve anne-babalar ve öğretmenler arasında içe kapanma $(\mathrm{r}=0.18)$ alt ölçeği dişında, hırçınlık ( $\mathrm{r}=0.49)$, hiperaktivite $(\mathrm{r}=0.47)$, streotipi $(\mathrm{r}=0.45)$ ve uygun olmayan konuşma $(\mathrm{r}=0.39)$ alt ölçeklerinin tümünde, pek çok araştırmaya göre daha yükssek düzeyde korelasyonlar elde emişlerdir. Bu bulgu, Aman ve arkadaşlarının bir diğer çalışmalarının bulgularıyla tutarlılık göstermektedir (Aman ve ark., 1987: Akt., Freund ve Reis, (1991).

Öğretmen ve anne-baba değerlendirmeleri arasındaki farklılıklar, çocukların davranış problemleriyle ilgili resmin bütününü görmek açısından önemlidir. Diğer taraftan bu farklılıklar, araştırmalarda farklı ölçme araçlarının kullanılmasından da kaynaklanmaktadır. Örneğin, pek çok araştırmada anne-babalar ve öğretmenler Achenbah ve Edelbrook'un annebaba ve öğretmen formlarını kullanılmıştır. Bu iki ölçeğin alt ölçekleri her ne kadar benzer isimleri taşısalar da özdeş maddelerden oluşmamaktadırlar. $\mathrm{Bu} \mathrm{da}$, araştırma sonuçlarının kıyaslanırlığıyla ilgili kuşkulara neden olabilmektedir.

Her çalışmada olabildiği gibi bu çalışmanın da bazı sınırlılıkları vardır. Çalışma grubumuz, farklı düzeyde yetersizliği olan zihinsel engelli çocuklardan oluşmaktadır. Araştırmalar, tanı koyulmuş çocuklar arasında içe yönelim yerine dışa yönelim sorunları olanlarda, hafif problem 
davranışlardan çok ağır sorunları olanlarda anne-baba ve öğretmen görüşleri arasındaki tutarlılığın yükseldiğini göstermektedir (Örn., Hundert ve ark., 1997; Keogh ve Bernheimer, 1998; Merrel ve Popinga, 1997; Vostanis ve ark., 1996). Bir diğer deyişle, engelin derecesi arttıkça daha ciddi sorunlar ile karşılaşılmaktadır. $\mathrm{Bu}$ nedenle, engelli bireylerin gelişimsel psikopatolojileriyle ilgili daha sofistike bilgilere ulaşılabilmesi açısından, ileri çalışmalarda zihinsel engelli çocuklar için özel olarak geliştirilmiş araçlar kullanarak engel türlerinin ve derecelerinin dikkate alınmasında yarar vardir.

Ayrıca yaş ranjı da çok geniştir. Araştırmalar, bilgi kaynakları arasındaki görüş birliğinin büyük çocuklardan daha çok küçük çocuklar için daha yüksek olduğunu göstermektedir (Blacher-Dixon ve Simeonsson, 1981; De Los Reyezs ve Kazdin, 2055; Hundert ve ark., 1997). Bu nedenle, farklı engel gruplarından, farklı yaş ve cinsiyet gruplarını temsil eden örneklemler üzerinde çalışmanın tekrarlanması daha güvenilir bilgilere ulaşılmasını sağlayacaktır.

Araştırma, öğretmenlerin ve anne-babaların çocukların değerlendirilmesine katkıda bulunabilecek kişisel özellikleri içermemiştir. Çocukların davranışlarına ilişkin algılarını etkileyen bilgi kaynaklarının pek çok özelliği olduğu bilinmektedir. Bu nedenle, farklı bilgi kaynaklarının görüşlerine başvururken, onların özelliklerini de dikkate almak gerekmektedir. Örneğin, eğer anne-babada bir psikopatoloji varsa, ya da anne-baba ve öğretmenin çocuktan beklentileri farklı ise bu durum çocuğa ilişkin algıyı etkileyecektir. Bazı araştırmalar (Örn., Blacher ve Simeonsson, 1981; Cai ve ark., 2003), çocuğun (Örneğin., yaş, cinsiyet, engelli olup olmama, engel türü ve derecesi, eğitim ortamı vb gibi) ve ailenin (fiziksel ve ruhsal sağlık, sosyoekonomik düzey gibi) özelliklerinin ölçek düzeyinde anne-baba ve öğretmen tutarlılığını etkilediğini göstermektedir (DeLos Reyezs ve Kazdin, 2005; Smith, 2007; McGraw ve ark., 2007).

Özellikle zihinsel engelli çocukların problem davranışlarını belirlemek amaciyla geliştirilmiş ve özdeş maddelerden oluşan anne-baba ve öğretmen formu bulunan dereceleme ölçeklerinin kullanılması, bu çocukların belirli davranışlarının kıyaslanmasını sağlayacaktır. Geçerli ve güvenilir dereceleme ölçekleri farklı bilgi kaynaklarına uygulanabilmesi, pek çok kişiden veri toplanabilmesi, standart uygulama, yanıtlama ve değerlendirme işlemleri olması nedeniyle oldukça yaygın kullanılmaktadırlar. Ancak, dereceleme ölçeklerinin yanı sıra, gözleme dayalı ve boylamsal çalışmalarla öğretmenlerin ve anne-babaların değerlendirmelerinin güvenirliği, zaman içindeki gelişimi ve çocukların cinsiyetlerine ve yaşlarına (gelişimsel özelliklerine göre) göre bilgi kaynaklarının değerlendirmelerinin değişip 
değişmediği belirlenebilir. Ayrıca, engelli ve engelli olmayan çocuklardaki duygusal ve davranışsal problemlerin yaygınlığının belirlenmesi de önleme ve müdahale hizmetlerinin düzenlenmesi açısından da önemlidir.

Problem davranışa müdahale edecek olan uzmanlar, anne-baba, öğretmen gibi farklı bilgi kaynaklarından gelen bilgileri nasıl değerlendirmelidir? $\mathrm{Bu}$ durumda, bilgi kaynakları arasındaki farkın büyüklüğü incelenebilir. Dereceleyicilerden birinin değerlendirmesi, diğerinkinden daha fazla problem davranışa işaret ediyorsa, bu davranışların bağlamı daha ayrıntılı olarak incelenebilir.

Sınırlılıklarına rağmen, bu çalışmanın önemli bazı kazanımlarından da söz edebiliriz. Anne-babalar ve öğretmenler çocuklarıyla iki farklı ortamda farklı rollere dayalı işlevlerle ve farklı beklentilerle etkileşime girmektedirler. $\mathrm{Bu}$ nedenle, bu iki bilgi verici kaynağın çocuğun davranışlarının farklı yönleriyle ilgili farklı görüşleri olabilir. Bu farklılıklar, eğitimcilere ve ruh sağlı̆̆ 1 uzmanlarına bilgi kaynaklarının beklentileriyle, ortamın özellikleriyle ilgili bilgi verir, önleyici ve müdahale edici hizmetlerin düzenlenmesine katkıda bulunabilir.

\section{SONUÇ}

Bulgularımız, genel olarak anne-baba ve öğretmen değerlendirmeleri arasındaki tutarlılı̆̆ın içe yönelimden problemlerinden daha çok dişa yönelim sorunlarıyla ilgili olduğu gözlenmiştir. Bunun yanı sıra, elde edilen korelasyonların düşük olması bilgi kaynaklarına, çocuğa ve içinde bulunulan bağlama ilişkin değişkenlerin etkisinin incelenmesi gerektiğini düşündürtmektedir.

\section{KAYNAKÇA}

Acar, Ç. (2000). Zihin özürlü çocuklarla çalışan özel eğitim öğretmenlerinin sınıflarında karşılaştıkları problem davranışlarla ilgili görüş ve önerileri. Yayınlanmamış Yüksek Lisans Tezi, Anadolu Üniversitesi Eğitim Bilimleri Enstitüsü.

Acar, Ç. ve Batu, S. (2001). Özel eğitim öğretmenlerinin sınıflarında karşılaştıkları problem davranışlarla ilgili görüş ve önerileri. 10. Ulusal Özel Eğitim Kongresi Bildirileri (Mart 2001): Antakya, Hatay, sf. 8695.

Aman, M. G. Tasse, M. J: Rojahn, J. ve Hammer; D. (1996). The Nisonger CBFR: a child ehavior rating form for children with developmental disailities. Research In Developmental Disailities, 17 (1), 41-57. 
Antshel, K. M. , Phillips, M. H., Gordon, M., Barkley, R. ve Faraone, S. V. (2006). Is ADHD a valid disorder in children with intellectual delays? Clinical Psychology Review, 26, 555-572.

Başal, H. A. ve Taner, M. (2007). Okul öncesi eğitim kurumlarına devam eden 5-6 yaş çocuklarda sinıfta gözlenen davranış bozuklukları. 17. Ulusal Özel Eğitim Kongresi Kongre Kitabı (15-17 Kasım 2007), Çeşme, İzmir.sf 50.

Blacher-Dixon, J. ve Simeonsson, R. J. (1981). Consistency and correspondence of mothers' and teachers' assessment of young handicapped children. Journal of Early Intervertion, 3, 64-71.

Bhatia, K., Kabra, M. ve Sarpa, S. (2005). Ehavioral problems in children with Down Syndrome. Indian Pediatrics, 42 (17), 675-680.

Cai, X., Kaiser, A. P. ve Hancock, T. B. (2004). Parent and teacher agreement on Child Behavior Checklist in a sample of preschoolers from low income and predominantly African American families. Journal of Clinical Child and Adolescent Psychology, 33 (2), 302-312.

Cederblad, M., Pruksachatkunakorn, P., Boripunkel, T., Intraprasert, S. ve Höök, B. (2001). Behavior problems and competence in Thai children and youths: teachers', parents' and subjects' perspectives. Transcultural psychiatry, $38(1), 64-79$.

Clark, D. ve Wilson, G. N. (2003). Behavioral assessment of children with Down syndrome using Reis Psychopathology Scale. American Journal of Medical Genetics, 118A, 210-216.

Coe, D. A., Matson, J. L., Russel, D. W., Slifer, K. J., Capone, G. T., Baglio, C. ve Stalling, S. (1999). Behavior problems of children with Down Syndrom and life events. Journal of Autism and Developmental Disorders, 29 (2), 149-156.

Costello, H., ve Bouras, N. (2006). Assessment of mental health problems in people with intellectual disabilities. Israelian Psychiatry Related Sciences, 43 (4), 241-251.

Costenbader, V. K. ve Kelly, H. R. (1990). Behavioral ratings of emotionally handicapped, learning disabled, and nonreferred children: Scale and source consistency. Journal of Psychoeducational Assessment, 8, 485496.

Crinic, K., Hoffman, C., Gaze, C. ve Edelbrock, C. (2004). Understanding the emergence of behavior problems in young children with developmental delays. Infants and Young children, 17 (3), 223-235.

Cuskell, M. ve Dads, M. R. (1992). Behavior problems in children with Down Syndrome and their siblings. Journal of Child Psychology and Psychiatry, 33 (4), 749-761. 
Çiçekçi, A. (2000). 10-15 yaş grubundaki engelli bireyler ile engelli olmayan bireylerin davranış problemlerinin karşılaştırmalı olarak incelenmesi. Yayınlanmamış Yüksek lisans Tezi. Ankara Üniversitesi, Sosyal Bilimler Enstitüsü. Ankara.

Çiftçi, İ. ve İnce, N. (2002). Zihinsel engelli öğrencilerin davranış problemlerinin öğretmen adayları tarafından incelenmesi. XXII. Ulusal Özel Eğitim Kongresi (112 Kasım 2002): Ankara, sf. 149-162.

Çiftçi, İ. ve Tabak, Ö. (1997). Zihinsel engellilerde görülen problem davranışların belirlenmesi. Özel Ĕ̈itim Günleri Bildiri kitabı. Kasım, 1997, 47-48.

Dekker, M. C., Nunn, R. J., Einfeld, S. E., Tonge, B. J. ve Koot, H. M. (2002). Assessing emotional and behavioral problems in chiydren with intellectual disability: revisiting the factor structure of the developmental behavior checklist. Journal of Autism and Developmental Disorders, 32 (6), 601-610.

Dekker, M. C., Nunn, R. J., ve Koot, H. M. (2002). Psychometric properties of the revised Developmental Behavior Checklist scales in Dutch children with intellectual disability. Journal of Intellectual Disability, $46(19,61-75$.

De Los Reyezs, A. ve Kazdin, A. E. (2005). Informant discrepancies in the assessment of childhood psychopathology: A critical review, theoretical framework, and recommendations for further studies. Psychological Bulletin, 131 (4), 483-509.

Dykens, E. M. (2000). Annotation: Psychopathology in children with intellectual disailitiy. Journal of Child Psychology and Psychiatry, 41 (4), 400-417.

Emerson, E. ve Hatton, C. (2007). Mental health of children and adolescents with intellectual disabilities in ritain. The British Journal of Psychiatry, 191, 493-499.

Epstein, M. H., Cullinan,D. ve Polloway, E. A. (1986). Patterns of maladjustment among mentally retarded children and youth. American Journal of mental Deficiency, 91 (2), 127-134.

Erbaş, D., Turan, Y., Aslan, Y. ve Dunlap, G. Attributions for Problem Behavior as Described by Turkish Teachers of Special Education. Remedial and Special Education. Basklda.

Fee, V. E. (1993). The differential validity of hperactivity/attention deficits and conduct problems among mentally retarded children. Journal of Anormal Child Psychology, 21 (1), 1-11.

Fee, V. E.,Matson, L. Moore, L. A. ve Benavidez, D. A. (1993). The differential validity of hyperactivity/attention deficits and conduct 
prolems among mentally retarded children. Journal of Abnormal Child Psychology, 21 (1), 1-11.

Freund, L. S. ve Reis, A. L. (1991). Rating prolem behaviors in outpatients with mental retardation: Use of the Aberrant Behavior Checklist. Research in Developmental Disabilities, 12, 435-451.

Gagnon, C., Vitaro, F. ve Tremblay, R. E. (1992). Parent-teacher agreement on kindergarteners' behavior-prolems: A research note. Journal of Child Psychology and Psychiatry, 33 (7), 1255-1261.

Gumley, G. A. (1986). Behavior prolems in retarded children with special reference to Down syndrome. British Journal of Psychiatry, 149, 156161.

Handen, . L. Feldman, R. S. ve Honigman, A. (1987). Comparison of parent and teacher assessment of developmentally delayed children's behavior. Exceptional Children, 54 (2), 137-144.

Hashino, K., Uda, J., Iwasaka, H., Ito, N., Sakiyama, S., Kitera, K., Matsumoto, H., Tsujimoto, H., Ikawa, G. ve Kishimoto, T. (1997). A study of cognitive development and behavior problems in mentally retarded children. Psychiatry and Clinical Neudosciences, 51, 57-65.

Hundert, J., Morrison, L., Mahoney, W., Mundy, F. ve Vernon, M. L. (1997), Topics in Early Childhood Special Education, 17 (4), 419-434.

Kaner, S. (1999). Yeniden Değerlendirilmiş Davranış Problemleri Kontrol Listesinin ülkemize uyarlanması. 9. Ulusal Özel Ĕgitim Kongresi. 22-23 Kasım 1999.Eskişehir.

Kaner ve Büyüköztürk (2008). Yenilenmiş Davranış Problemleri Kontrol Listesi'nin ülkemize uyarlanması. Yayınlanmamış Araştırma Raporu.

Kaner, S., Uçak-Çiçekçi, A. (2000). Yeniden Değerlendirilmiş Davranış Problemleri Kontrol Listesinin ülkemize uyarlanması. Özel Eğitim Dergisi, 2 (4),23-34.

Keogh, B. K. ve Bernheim, L. P. (1998). Concordance between mothers' and teachers' perceptions of behavior problems of children with developmental delays. Journal of emotional and behavioral disorders, 6 (33), 33-41.

Kerker, B. D. Qwens, P. L. Zigler, E. ve Horwitz, S. M. (2004). Mental health disorders among individuals with mental retardation: Challenges to accurate prevalance estimates. Pulic Health Report, 119, 409-417.

Liepman, M. C. ve Ort, M. (1980). Assessment of handicaps in mentally retarded children: Preliminary findings from a study using the Schedule of Children's Handicaps, ehavior and Skills. Acta Psychiatrica Scandinavia, 62 (285), 187-195).

Masi, G. (1998). Psychiatric illness in mentally retarded adolescents: Clinical features. Adolescence, 6 (22), 57-71. 
Matson, J. L., Minshawi, N. F., Gonzales, M. L. ve Mayville, S. B. (2006). The relationships of comorbid problem behaviors to social skills in persons with profound mental retardation. Behavior Modification, 30 (4), 496-506.

Mattison, R. E., Bagnato, S. J., ve Strickler, E.(1987). Diagnostic importance of combined parent and teacher ratings of the Revised Behavior Problem Checklist. Journal of Abnormal Child Psychology, 15 (4), 617628.

McGraw, S., Shaw, T. ve Beckley, K. (2007). Prevalence of psychopathology across a service population of parents with intellectual disabilities and their children. Journal of Policy and Practice in Intellectual Disabilities, 4 (1), 11-22.

Merrel, K. W. ve Popinga, M. R. (1994). Parent-teacher concordance and gender differences in behavioral ratings of social skills and socialemotional problems of primary-age children with disabilities. Assessemnt for Effective Intervention, 19 84), 1-14.

Özen, A., Çolak, A. ve Acar, Ç. (2002). Zihin özürlü çocuğa sahip annelerin günlük yaşamda karşılaştıkları problem davranışlarla ilgili görüşleri. Ankara Üniversitesi Ĕgitim Bilimleri Fakültesi Özel Ĕgitim Dergisi, 3 (2), 1-13.

Polloway, E. A., Epstein, M. H. ve Cullinan, D. (1985). Prevalence of behavior problems among educable mentally retarded students. Education and Training of Mentally Retarded, March, 3-14.

Quay, H. C. ve Peterson, D. R. (1996). Revised Behavior Problem Checklist. Professional Manual. Odesa: PAR.

Ruiter, K. P., Dekker, M. C., Douma, J. C. H. , Verhultz, F. C. ve Koot, H. M. (2008). Development of parent-and-teacher-reported emotional and behavioral problems in young people with intellectual disabilities: Does level of intellectual disability matter? Journal of Applied Research in Intellectual Disabilities, 21, 70-80.

Rush, K. S. Bowman, L. G. Eidman, S. L. Toole, L. M. Mortenson, B. P. (2004). Assessing psychopathology in individuals with developmental disailities. Behavior Modification, 28 (5), 621-637.

Singh, N. N., Sood, A., Sonenklar, N. ve Ellis, C. R. (1991). Asssessment and diagnosis of mental illness in persons with mental retardation. Behavior Modification, 15 (3), 419-443.

Smith, S. R. (2007). Making sense of multiple informants in child and adolescent psychopathology, Journal of Psychoeducational Assessment, 25 (2), 139-149. 
Stateke, H., Yoshida, K., Yamashita, H., Kinukawe, N. ve Takagishi, T. (2003). Agreement between parents and teachers on behavioral/emotional prolems in Japanese school children using the Child Behavior Checklist. Child Psychiatry and Human Development, 34 (2), 111-126.

Treuting, M. V. ve Elliott, S. N. (1997). Social behavior ratings of at at-risk preschool children: comparisons with typical preschool children by parents and teachers. Canadian journal of School Psychology, 13 (1), 68-84.

Vatter, (1998). Pschiatric disorders in persons with Down Syndorome: A review of studies. http://www.altonwe.com/cs/downsyndrome/psychoin.html . 2008.

Verhultz, F. C. ve Akkerhuis, G. W. (1989). Agreement etween parents' and teachers' ratings of behavioral-emotional problems of children aged 412. Journal of Child Psychology and Psychiatry, 23 (1), 123-136.

Verhultz, F. C., ve Ende, J. (1992). Agreement between parent' reports and adolescents' self-reports of problem behavior. Journal of Child Psychology and Psychiatry, 33 (6), 1011-1023.

Vostanis, P., Bickerton, W., Cumella, S., Chung, M. C., Winchester, C. ve Doran, J. (1996). Mother and teacher ratings of maladaptive behaviorsin children with special needs. Eurepean Journal of Special Needs Education, 11 (1), 117-124.

Whitaker, S. ve Read, S. (2006). The prevalance of psychiatric disorders among people with intellectual disabilities: An analyisis of the literature. Juornal of Applied Research in Intellectual Disabilities, 19, 330-345.

Yaluğ, İ. ve Tufan, A. E. (2005). Zeka geriliği ve psikoz komoriditesi: Tanısal gölgelemenin neresindeyiz? Anadolu Psikiyatri Dergisi, 6 (267273).

Yıkmış, A. ve Ural, A. (2004). öğretmen adayları görüşlerine göre öğretmenlerin karşılaştıkları prolem davranışlar ve çözüm yaklaşımları. XIV. Özel Eğitim Kongresi. Abant İzzet Baysal Üniversitesi. 4-6 Kasım 2004. Bolu. 
